\title{
SOME BLOOD MARKERS OF THE FUNCTIONAL STATE OF LIVER IN DAIRY COWS WITH CLINICAL KETOSIS
}

\author{
M. SIMONOV \& V. VLIZLO \\ Institute of Animal Biology of the National Academy of Agrarian Sciences \\ of Ukraine, Lviv, Ukraine
}

\section{Summary}

Simonov, M. \& V. Vlizlo, 2015. Some blood markers of the functional state of liver in dairy cows with clinical ketosis. Bulg. J. Vet. Med., 18, No 1, 74-82.

Metabolic disorders in animals are one of the most important problems in modern cattle production. The paper presents results characterising the functional state of the liver in dairy cows with clinical ketosis. The study was conducted on 17 Holstein cows (9 of them were clinically healthy with negative test for ketone bodies in urine and 8 with positive test) in their second to fourth lactation with milk yield above $8,000 \mathrm{~kg}$ per previous lactation. Conducted research has shown that cows affected with ketosis, had hypoglycaemia, dysproteinaemia, hypoalbuminaemia, increased liver enzymes and higher blood content of aromatic and sulfur-containing amino acids. Herewith the activity of cholinesterase and phospholipids were decreased. Albumins-globulins ratio and esterified to total cholesterol ratio was decreased in conditions associated with liver pathology due to clinical ketosis. Sick cows had signs of secondary osteodystrophy. Obtained results allowed us concluding that dairy cows ketosis caused significant changes in structural and functional state of liver, associated with abnormalities in of serum proteins synthesis, disturbed metabolism of amino acids, lipids and calcium.

Key words: amino acids, calcium, clinical ketosis, cows, lipids, liver pathology, proteins

\section{INTRODUCTION}

In all countries with extensive development of dairy cattle breeding, metabolic disorders are among the major obstacles to increase in milk yields. These diseases cause significant economic losses in the sphere of breeding because of lower calfcrop underproduction of milk, rise of production costs and decreased profitability of dairy cattle breeding (Ferguson, 2001). Analysis of some statistical data
(Ferguson, 2001; Geishauser et al., 2001; Levchenko \& Sahniuk, 2002) showed that in high yielding herds $50 \%$ of parturient cows suffered from one-two or more diseases. Moreover, ketosis is a polyetiological disease, often complicated by other diseases. Impaired functions of liver, pancreatic gland, other organs are often observed in sick animals (Steen, 2001; Stojević et al., 2005; Loor et al., 2007; 
Gonzalez \& Rosendo, 2013) which may complicate diagnostics and further treatment.

Most commonly ketosis in high yielding cows is accompanied by fatty liver dystrophy (Vlizlo, 1998; Levchenko \& Sahniuk, 2002), particularly in periods of highest energy deficit. If a cow uptakes insufficient quantity of food, the organism uses its own reserves and at first uses fats that decompose to free fatty acids (Mc Art et al., 2013). With the bloodstream they travel to liver and muscles, where they are used as a source of energy. In case when there is insufficient quantity of propionates, which are synthesised in rumen from easily digested carbohydrates, free acids are decomposed to ketone bodies (acetone, $\beta$-hydroxybutyric acid and acetoacetic acid) and ketosis develops, or lipid deposits in liver and hepatosteatosis occur (Li et al., 2012; Gonzalez \& Rosendo, 2013). The concentration of ketone bodies in urine or milk, serum concentration of glucose and fat content in milk are among the main laboratory diagnostic parameters of ketosis in dairy cows, which are used by veterinarians in Ukraine. Herewith these parameters may only indirectly indicate on liver pathology.

Our research objective was to determine changes in diagnostic parameters of the functional state of liver in dairy cows with clinical ketosis.

\section{MATERIALS AND METHODS}

The study was performed in March on seventeen Holstein cows in their second to fourth lactation with milk yield above $8,000 \mathrm{~kg}$ per previous lactation. Animals were kept in similar conditions and received the same diet. Clinical examination of cows was performed and the content of ketone bodies (acetoacetic acid) in urine was detected with diagnostic strips (Ketophan, Pliva). During examination it was revealed that some animals $(n=8)$ were lying up, exhibited quick loss of live weight and yield, and looked depressed, some of them had muscular tremor. The urinalysis indicated presence of ketone bodies. Animals with positive results for ketone bodies in urine were selected into a separate group. Blood samples were withdrawn 2 or 3 weeks after calving from the jugular vein before the morning feeding, in sterile tubes. The levels of glucose, total protein, calcium, total cholesterol, estherified cholesterol and total bilirubin and activities of aspartate aminotransferase, $\gamma$-glutamyltransferase, cholinesterase and alkaline phosphatase were determined in blood serum on a biochemical analyser Humalyzer 2000 (Germany). The plasma level of free amino acids was determined on an amino acid analyser Biotronik LC 6001 (Germany). The protein fractions were assayed by protein fractionation in polyacrylamide gel. The content of calcitonin and parathormone in plasma was measured using enzyme multiplied immunoassay and DRG test kits (Germany). The content of triglycerols was assessed colorimetrically (reaction with chromotropic acid), the level of unesterified fatty acids - colorimetrically (reaction with 1,5-diphenylcarbazide). Blood phospholipids were determined using thin layer chromatography.

Results were processed statistically in Excel, presented as arithmetic mean value and standard error of the mean (SEM). The significance of the difference between two groups was calculated.

\section{RESULTS}

Conducted laboratory results showed that blood glucose level was significantly 
lower (by 29.3\%; $\mathrm{P}<0.01$ ) in ketotic cows in comparison with healthy ones (Fig. 1).

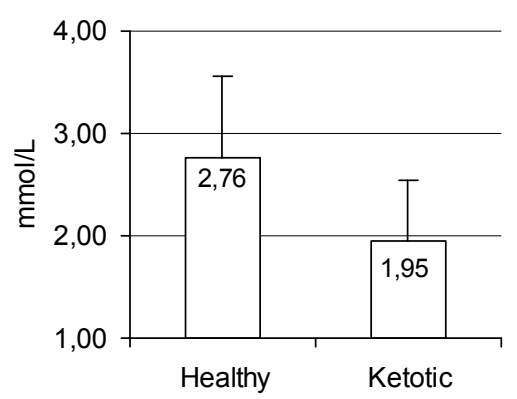

Fig. 1. Serum glucose content in cows affected with ketosis $(n=8)$ and healthy cows $(n=9)$. Data are presented as mean $\pm \mathrm{SD}$.

The results of conducted research revealed significant increase of the level of total serum protein (by $13.8 \%$; $\mathrm{P}<0.001)$ in newly calved cows with ketosis in comparison with clinically healthy cows (Table 1). Dysproteinaemia in ketotic cows was characterised by reduction of albumin content (by $30.8 \%$; $\mathrm{P}<0.01$ ) and increased alpha-globulins (by $35.1 \%$; $\mathrm{P}<0.01$ ), beta-globulins (by $38.9 \%$; $\mathrm{P}<0.001$ ) and gamma-globulins (by $38.1 \%$; $\mathrm{P}<0.001)$ in blood serum. The albuminglobulin ratio decreased up to 0.4 in sick animals in comparison with 0.94 in healthy ones.
The analysis investigation of plasma amino acid content in sick cows revealed significant increase in phenylalanine (by $18.5 \%$; $\mathrm{P}<0.05$ ), tryptophan (by $32.0 \%$; $\mathrm{P}<0.01$ ) and methionine (by $30.6 \%$; $\mathrm{P}<0.01$ ) concentrations (Table 1 ).

The total serum bilirubin level in cows affected with ketosis was 4-fold higher in comparison with healthy animals (Fig. 2).

Conducted study showed (Table 2) significant distinctions of serum enzymes activities between healthy and ketotic cows. In particular, activity of aspartate aminotransferase (AST) was significantly $(\mathrm{P}<0.001)$ higher $(2.5$-fold $)$. Moreover, activity of AST exceeded the upper physiological limit in $85.4 \%$ of studied sick animals. Also, serum activity of gamma-glutamyl transferase (GGT) was increased in more than $87 \%$ of animals. Serum activity of cholinesterase in ketotic dairy cows was significantly decreased by $41.3 \% \quad(\mathrm{P}<0.001)$ in comparison with clinically healthy animals. Moreover, activity of this enzyme in $82 \%$ of animals with signs of ketosis was under the lower physiological range. Laboratory examination showed a significant increase (by $29.1 \%$; $\mathrm{P}<0.001$; Table 2 ) of serum alkaline phosphatase activity in ketotic cows.

Total calcium content in serum of ketotic cows was by $18.2 \%$ lower $(\mathrm{P}<0.001)$ (Fig. 3). It was accompanied by

Table 1. Parameters of protein metabolism in cows affected with ketosis $(n=8)$ and healthy cows $(\mathrm{n}=9)$. Data are presented as mean $\pm \mathrm{SD}$

\begin{tabular}{lccc}
\hline Parameter & Healthy & Ketotic & \\
\hline Total protein, g/L & $76.2 \pm 2.19$ & $88.4 \pm 1.42$ & $\mathrm{P}<0.001$ \\
Albumins, g/L & $37.0 \pm 2.69$ & $25.6 \pm 1.66$ & $\mathrm{P}<0.01$ \\
$\alpha$-globulins, g/L & $10.0 \pm 1.02$ & $15.4 \pm 1.42$ & $\mathrm{P}<0.01$ \\
$\beta$-globulins, g/L & $10.7 \pm 0.80$ & $17.5 \pm 0.61$ & $\mathrm{P}<0.001$ \\
$\gamma$-globulins, g/L & $18.5 \pm 1.29$ & $29.9 \pm 1.12$ & $\mathrm{P}<0.001$ \\
Phenylalanine, $\mu \mathrm{mol} / \mathrm{L}$ & $24.3 \pm 0.53$ & $29.8 \pm 2.64$ & $\mathrm{P}<0.05$ \\
Tryptophan, $\mu \mathrm{mol} / \mathrm{L}$ & $38.6 \pm 2.95$ & $56.8 \pm 4.40$ & $\mathrm{P}<0.01$ \\
Tyrosine, $\mu \mathrm{mol} / \mathrm{L}$ & $27.6 \pm 2.05$ & $31.1 \pm 5.64$ & - \\
Methionine, $\mu \mathrm{mol} / \mathrm{L}$ & $16.8 \pm 1.48$ & $24.2 \pm 1.42$ & $\mathrm{P}<0.01$ \\
\hline
\end{tabular}


increased parathormone concentrations (by $43.1 \%$; $\mathrm{P}<0.001$; Fig. 4) as well as lower level of calcitonin (by 27.7\%, $\mathrm{P}<0.001$; Fig. 5).

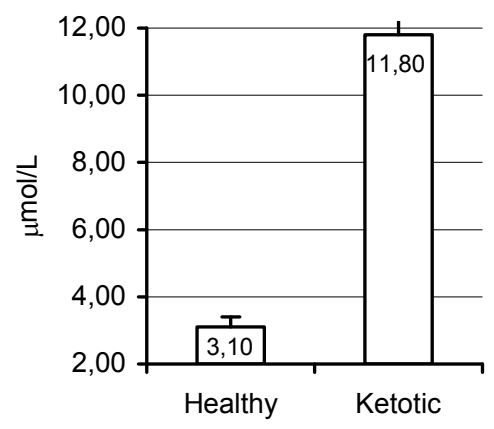

Fig. 2. Serum levels of total bilirubin in cows affected with ketosis $(\mathrm{n}=8)$ and healthy cows $(n=9)$. Data are presented as mean \pm SD.

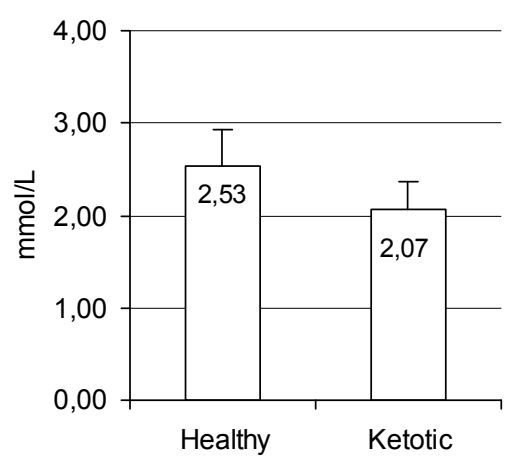

Fig. 3. Content of total calcium in serum of cows affected with ketosis $(n=8)$ and healthy cows $(n=9)$. Data are presented as mean \pm SD.

Conducted examination of lipid metabolism parameters in blood revealed a range of distinctions between sick and healthy cows. In particular, significantly higher ( 3 -fold; $\mathrm{P}<0.01)$ contents of triglycerols and unesterified (free) fatty acids (by 36.4\%; $\mathrm{P}<0.001$; Table 3) were observed. Total cholesterol content was also increased (by $46 \% ; \mathrm{P}<0.01$ ). No significant changes in the level of esterified cholesterol were observed. Serum phospholipids content in cows affected with ketosis was significantly lower in comparison with clinically healthy animals (by $43.8 \%$; $\mathrm{P}<0.05$; Table 3 ).

\section{DISCUSSION}

Hypoglycaemia in ketotic cows is considered as a result of discrepancy between energy supply with food and glucose requirements for metabolic processes and milk production. The mammary gland requires a significant quantity of glucose, predominantly used for synthesis of lactose during the lactation, particularly on its beginning. Moreover, as calving approaches, the blood level of progesterone is decreasing, whilst the oestrogen content remains high or even increases (Grummer, 1995). High blood oestrogen levels in cows is a principal regulator decreasing the appetite (Grummer, 1993).

Hypoalbuminaemia in cows is due to development of ketosis and gives evidence of hepatic function disorders, particularly impaired ability to synthesise serum albumin (Farag \& Metwally, 2012). Most

Table 2. Enzyme activity in blood of cows affected with ketosis $(n=8)$ and healthy cows $(n=9)$. Data are presented as mean $\pm \mathrm{SD}$

\begin{tabular}{lrrr}
\hline Parameter & Healthy & \multicolumn{1}{c}{ Ketotic } \\
\hline Aspartate aminotrasferase (AST), U/L & $36.5 \pm 2.94$ & $91.8 \pm 5.14$ & $\mathrm{P}<0.001$ \\
$\gamma$-glutamyltransferase (GGT), U/L & $12.8 \pm 0.88$ & $27.2 \pm 2.21$ & $\mathrm{P}<0.001$ \\
Cholinesterase, U/L & $70.9 \pm 1.90$ & $41.6 \pm 4.63$ & $\mathrm{P}<0.001$ \\
Alkaline phosphatase, U/L & $174.7 \pm 5.87$ & $246.4 \pm 11.49$ & $\mathrm{P}<0.001$ \\
\hline
\end{tabular}




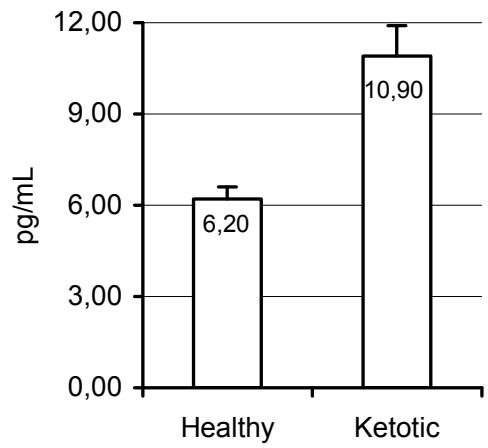

Fig. 4. Plasma parathormone concentrations in cows affected with ketosis $(n=8)$ and healthy cows $(n=9)$. Data are presented as mean \pm SD.

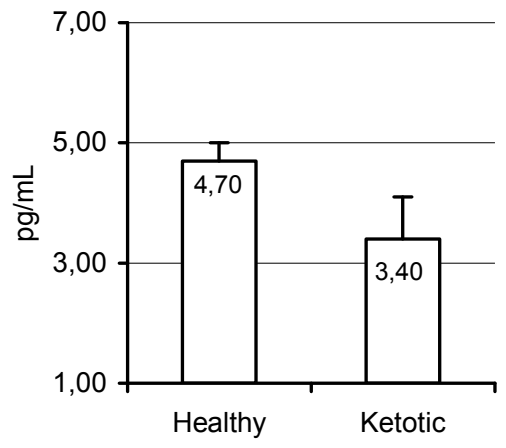

Fig. 5. Plasma calcitonin in cows affected with ketosis $(n=8)$ and healthy cows $(n=9)$. Data are presented as mean $\pm \mathrm{SD}$.

Table 3. Blood parameters of lipid metabolism in cows affected with ketosis $(n=8)$ and healthy cows $(\mathrm{n}=9)$. Data are presented as mean $\pm \mathrm{SD}$

\begin{tabular}{llll}
\hline Parameter & Healthy & Ketotic & \\
\hline Triglycerols, mmol/L & $0.22 \pm 0.031$ & $0.67 \pm 0.11$ & $\mathrm{P}<0.01$ \\
Unesterified fatty acids, mmol/L & $0.70 \pm 0.15$ & $1.10 \pm 1.12$ & $\mathrm{P}<0.001$ \\
Total cholesterol, mmol/L & $2.70 \pm 0.36$ & $5.00 \pm 0.41$ & $\mathrm{P}<0.01$ \\
Esterified cholesterol, mmol/L & $1.80 \pm 0.10$ & $1.70 \pm 0.19$ & - \\
Phospholipids, mmol/L & $1.60 \pm 0.31$ & $0.90 \pm 0.07$ & $\mathrm{P}<0.05$ \\
\hline
\end{tabular}

commonly, ketosis in high-yielding cows is accompanied with fat liver dystrophy (Hutjens \& Peirce, 2005). Increased blood content of aromatic and sulfur-containing amino acids also indicated disturbed functional state of liver. Phenylalanine, tryptophan, tyrosine and methionine belong to these groups of amino acids. The reason for increased content of these amino acids may be liver impairment, leading to lower concentration of intracellular enzymes in hepatocytes (which inactivate mentioned amino acids). Disturbances in degradation of aromatic and sulfur-containing amino acids result in excessive endotoxin formation, namely phenol, mercaptan, indole, which leads to further intensification of the pathological process (D'Mello, 2003). Nevertheless, increased methionine content has also its advantages, since this amino acid plays a significant role in the antioxidant defense system. The potent antioxidant effect of methionine is explained with the rich sulphur content, which inactivates free radicals, and increases lipids utilisation, preventing their deposition in liver and vascular walls. Synthesis of taurine and cysteine, a precursor of glutathione, depends on the level of methionine (Chen \& Dickman, 2005; Erdmann et al., 2005; El-Hattab et al., 2012).

Elevated activity of transaminases gives evidence that considerable proportion of cows, affected with ketosis, have destructive liver changes, resulting in an increase of transaminases release from cell organelles into blood. High serum activity of GGT in cows with signs of ketosis indicates on engorgement in hepatobiliary system. GGT catalyses the trans- 
fer of the glutamyl group and gammaglutamyl peptide to the acceptor peptide or amino acid. This enzyme has the highest activity in kidneys, liver and pancreatic gland, particularly in cells, forming renal tubules and bile ducts (Vlizlo et al., 1997).

In contrast to the activity of transaminases, the serum activity of cholinesterase in ketotic cows was significantly lower in comparison with healthy animals. Cholinesterase is a secretory enzyme, which activates the reaction of decomposition of choline esters (acetylcholine butyrylcholine) to choline and acetic or butyric acid. It is found almost in all tissues, but the highest activity is observed in blood plasma, liver and pancreatic gland. Diagnostic significance of serum cholinesterase is explained by the fact that it is synthesised in hepatocytes and functions in blood. Therefore, in case of liver damage, its activity in blood decreases (Stojević et al., 2005).

Obtained results on calcium homeostasis status (blood total calcium, calcitonin, parathyroid hormone, alkaline phosphatase) in cows affected with ketosis pointed out on the development of secondary osteodystrophy in animals. Hypocalcaemia in sick cows might be caused by disorders of vitamin D metabolism due to damage of organs, involved in its metabolism (liver, kidneys) (Walsh et al., 2007; Vlizlo, 1998). This is confirmed by the results from determination of alkaline phosphatase activity, which was significantly higher in cows with ketosis in comparison with healthy animals. Moreover, decreased total calcium content occurred due to activation of compensatory reactions, directed on reduction of the concentration of acidic metabolic products. Thus, binding of cations and acids takes place and they are excreted with urine in the form of organic acids, hydrogen phosphates and calcium phosphate (Vlizlo et $a l ., 2011)$. Under conditions of hypocalcaemia systemic compensatory mechanisms, enhancing restoration of the normal level of calcium in blood are activated. In particular, we have revealed a significantly higher blood level of parathormone and reduced level of calcitonin.

The excessive liberation of fatty acids promotes the formation of ketone bodies and cholesterol. Their concentration in blood plasma is associated with energy supply of animal organism and characterises the activity of lipolysis, their mobilisation from fat depot. Therefore, in case of inadequate systemic energy supply, activation of lipolysis occurs and the level of free fatty acids increases (González et al., 2011).

Concentration of cholesterol in blood serum depends on the state of liver (Sevinç et al., 2003). Increased blood serum cholesterol concentration (hypercholesterinaemia) may be associated with activation of lipogenesis and gluconeogenesis, formation of intermediate products, which might be used for synthesis of endogenous cholesterol (Lean \& De Garis, 2011). Also, it is noteworthy that the esterified/total cholesterol ratio decreased from 0.68 in healthy animals up to 0.34 in ketotic ones. The decrease in this index is an unfavourable prognostic sign, because it indicates significant injury of hepatocytes and impairment of their synthetic ability.

One of the causes of disorders in phospholipids synthesis is fat liver dystrophy, which is often associated with and caused ketosis (Vlizlo, 1998). The major part of phospholipids is used in liver for physiologic reparation processes, but a certain portion is transported to different organs and tissues through blood circulation 
(Gruffat et al., 1996). Lipotropic substances, which donate methyl groups directly participating in synthetic processes (choline, serine, methionine) or substances which promote synthesis (cyanocobalamine) are required for synthesis of phospholipids. Choline together with triacylglycerols forms choline phosphatides (lecithin), providing a permanent lipid outflow from liver to bloodstream and preventing the risk of liver fat dystrophy. With insufficient quantity of lipotropic substances in liver, neutral fats accumulate there and the quantity of glycogen decreases. At this the size of hepatocytes increases, cell membranes rupture and big steatocystomas appear. If the process progresses, connective tissue develops and gradually substitutes fat, leading to diffuse fibrosis. Hypoxia, which accompanies anaemia, cardiovascular or respiratory insufficiency, also contributes to disturbed phospholipids synthesis, inasmuch as due to hypoxia, deficit of energy (needed for lecithin synthesis) occurs and lipid metabolism is directed for synthesis of triacylglycerols. Disorders of phospholipid synthesis during hepatocyte injury are dependent not only on the deficiency of lipotropic substances, but also on the insufficient formation of ATP, the source of energy for synthetic processes, in liver cells (Lieberman et al., 2007; Contreras et al., 2010).

Summarising all abovementioned, we may conclude that the development of ketosis in dairy cows causes significant changes of functional state of liver, associated with disorders of synthesis of serum proteins (hypoalbuminaemia) and disturbance of metabolism of amino acids, lipids and calcium. Herewith the activity of indicator liver enzymes in serum significantly increases, indicating destructive changes. In case of liver pathology, cau- sed by clinical ketosis, albumin to globulin ratio and esterified to total cholesterol ratio are decreased.

\section{REFERENCES}

Chen, C. \& M. B. Dickman, 2005. Proline suppresses apoptosis in the fungal pathogen Colletotrichum trifolii. Proceedings of the. National Academy of Sciences of the USA, 102, 3459-3464.

Contreras, G. A., N. J. O'Boyle, T. H. Herdt \& L. M. Sordillo, 2010. Lipomobilization in periparturient dairy cows influences the composition of plasma nonesterified fatty acids and leukocyte phospholipid fatty acids. Journal of Dairy Science, 93, 25082516.

D'Mello, J. P. F., 2003. Amino Acids in Animal Nutrition. CABI Publishing, Edinburgh, UK.

El-Hattab, A. W., L. T. Emrick, W. J. Craigen \& F. Scaglia, 2012. Citrulline and arginine utility in treating nitricoxide deficiency in mitochondrial disorders. Molecular Genetics and Metabolism, 6, 399-406.

Erdmann, K., N. Grosser \& H. Schrzder, 2005. L-methionine reduces oxidant stress in endothelial cells: Role of hemeoxygenase1, ferritin, and nitric oxide. The AAPS Journal, 7, 18-19.

Farag, E. A. R. \& M. M. Metwally, 2012. Markers used for prediction of ketosis and milk fever in dairy buffaloes at Kaliobeia governorate. Global Veterinaria, 9, 1-7.

Ferguson, J. D., 2001. Nutrition an reproduction in dairy herds. In: Proceedings of the Intermountain Nutrution Conference, Salt Lake City, UT Utah State University, Logan, pp. 65-82.

Geishauser, T., K. Leslie, D. Kelton \& T. Duffield, 2001. Monitoring for subclinical ketosis in dairy herds. Compendium on Continuing Education for the Practising Veterinarian, 23, 65-71.

González, C. I. \& O. Rosendo, 2013. Assessment of Fatty liver syndrome and its 
predisposing factors in a dairy herd from Venezuela. ISRN Veterinary Science, http://dx.doi.org/10.1155/2013/191708.

González, F. D., R. Muiño, V. Pereira, R. Campos \& J. L. Benedito, 2011. Relationship among blood indicators of lipomobilization and hepatic function during early lactation in high-yielding dairy cows. Journal of Veterinary Science, 12, 251255.

Gruffat, D., D. Durand, B. Graulet \& D. Bauchart, 1996. Regulation of VLDL synthesis and secretion in the liver. Reproduction, Nutrition, Development, 36, 375389.

Grummer, R. R., 1993. Feed to avoid fatty liver and ketosis. Hoard's Dairyman Magazine, 23, 754.

Grummer, R. R., 1995. Impact of changes in organic nutrient metabolism on feeding the transition dairy cow. Journal of Animal Science, 73, 2820-2833.

Hutjens, M. F. \& E. Peirce, 2005. Caring for Transition Cows. Hoard's Dairyman Books, USA.

Lean, I. \& P. De Garis, 2011. Transition Cow Management: A review for nutritional professionals, veterinarians and farm advisers. Dairy Australia Ltd. http:/ /www.dairyaustralia.com.au/ /media/Docu ments/Animals\%20feed\%20and\%20enviro nment/Feed\%20and\%20nutrition/Nutrition $\% 20$ management/G2M\%20-\%20InCalf $\%$ 20transition $\% 20$ cow $\% 20 \mathrm{mgt} \% 20$ review\% 20-\%20low\%20res.pdf (23 June 2014 date last accessed)

Levchenko, V. I. \& V. V. Sahniuk, 2002. Ketoz u vysokoproduktyvnyh koriv: etiologia i diagnostyka. Veterinary Medicine of Ukraine, 2, 18 (UA).

Li, P., X. B. Li, S. X. Fu, C. C. Wu, X. X. Wang, G. J. Yu, M. Long, Z. Wang \& G. W. Liu, 2012. Alterations of fatty acid $\beta$ oxidation capability in the liver of ketotic cows. Journal of Dairy Science, 95, 17591766.

Lieberman, M., A. Marks \& C. Smith, 2007. Essentials of Medical Biochemistry, $2^{\text {nd }}$ edn, Lippincott Williams and Wilkins, Maryland, USA.

Loor, J. J., R. E. Everts, M. Bionaz, H. M. Dann, D. E. Morin, R. Oliveira, X. Vignon, S. L. Rodriguez-Zas, X. C. Tian, X. Yang, J.-P. Renard \& H. A. Lewin, 2007. Nutrition-induced ketosis alters metabolic and signaling gene networks in liver of periparturient dairy cows. Physiological Genomics, 32, 105-116.

McArt, J. A., D. V. Nydam, G. R. Oetzel, T. R. Overton \& P. A. Ospina, 2013. Elevated non-esterified fatty acids and $\beta$ hydroxybutyrate and their association with transition dairy cow performance. The Veterinary Journal, 13, 386-389.

Sevinç, M., A. Başoğlu, H. Güselbektaş \& M. Boydak, 2003. Lipid and lipoprotein levels in dairy cows with fatty liver. Turkish Journal of Veterinary and Animal Sciences, 27, 295-299.

Steen, A., 2001. Field study of dairy cows with reduced appetite in early lactation: Clinical examinations, blood and rumen fluid analyses. Acta Veterinaria Scandinavica, 42, 219-228.

Stojević, Z, J. Piršljin, S. Milinković-Tur, M. Zdelar-Tuk\& B. Ljubić, 2005. Activities of AST, ALT and GGT in clinically healthy dairy cows during lactation and in the dry period. Veterinarski Arhiv, 75, 67-73.

Vlizlo, V. V., 1998. Zyrovyi Gepatoz u Koriv. Kyiv (UA).

Vlizlo, V. V., G. Gotter \& V. Baumgartner, 1997. Patogenetychni mehanizmy vyneknennia gepatozu u laktuyuchyh koriv. Veterinary Medicine. Interdepartmental Topical Scientific Collection of Articles, 71, 56-60 (UA).

Vlizlo, V. V., I. M. Petruh \& M. R. Simonov, 2011. Pokaznyky mineralnogo obminu u koriv na riznyh fazah laktatsii ta periodah utrymannia. The Animal Biology,13, 6571 (UA).

Walsh, R. B., J. S. Walton, D. F. Kelton, S. J. LeBlanc, K. E. Leslie \& T. F. Duffield, 2007. The effect of subclinical ketosis in early lactation on reproductive perfor- 
Some blood markers of the functional state of liver in dairy cows with clinical ketosis

mance of postpartum dairy cows. Journal of Dairy Science, 90, 2788-2796.

Paper received 05.02.2014; accepted for publication 25.04.2014

\section{Correspondence:}

M. Simonov

Institute of Animal Biology

of the National Academy of

Agrarian Sciences of Ukraine,

Lviv, Ukraine

msimonov@inenbiol.com.ua 